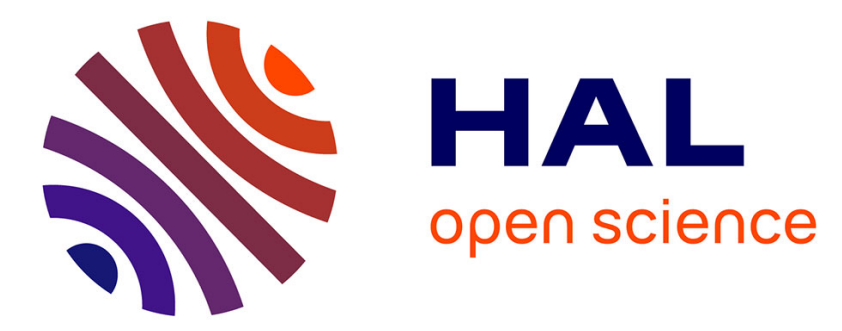

\title{
Jouer dans l'au-delà? Le mobilier ludique des sépultures de Gaule méridionale et de Corse (Ve siècle av. J.-C. - Ve siècle apr. J.-C.)
}

Yves Manniez

\section{- To cite this version:}

Yves Manniez. Jouer dans l'au-delà? Le mobilier ludique des sépultures de Gaule méridionale et de Corse (Ve siècle av. J.-C. - Ve siècle apr. J.-C.). Archimède: archéologie et histoire ancienne, 2019, 6, pp.186-198. halshs-02927517

\section{HAL Id: halshs-02927517 https://shs.hal.science/halshs-02927517}

Submitted on 1 Sep 2020

HAL is a multi-disciplinary open access archive for the deposit and dissemination of scientific research documents, whether they are published or not. The documents may come from teaching and research institutions in France or abroad, or from public or private research centers.
L'archive ouverte pluridisciplinaire HAL, est destinée au dépôt et à la diffusion de documents scientifiques de niveau recherche, publiés ou non, émanant des établissements d'enseignement et de recherche français ou étrangers, des laboratoires publics ou privés. 


\section{ARCHIMĖDE No6

1 DOSSIER THÉMATIQUE :

HISTOIRES DE FIGURES CONSTRUITES : LES FONDATEURS DE RELIGION

DOSSIER THÉMATIQUE :

JOUER DANS L'ANTIQUITÉ : IDENTITÉ ET MULTICULTURALITÉ

GAMES AND PLAY IN ANTIQUITY: IDENTITY AND MULTICULTURALITY

71 Véronique DASEN et Ulrich SCHÄDLER

Introduction

\section{EGYPTE}

75 Anne DUNN-VATURI

Aux sources du « jeu du chien et du chacal »

89 Alex DE VOoGT

Traces of Appropriation: Roman Board Games in Egypt and Sudan

100 Thierry DEPAULIS

Dés coptes ? Dés indiens?

MONDE GREC

113 Richard. H.J. ASHTON

Astragaloi on Greek Coins of Asia Minor

127 Véronique DASEN

Saltimbanques et circulation de jeux

144 Despina IGNATIADOU

Luxury Board Games for the Northern Greek Elite

160 Ulrich SCHÄDLER

Greeks, Etruscans, and Celts at play

MONDE ROMAIN

175 Rudolf HAENSCH

Spiele und Spielen im römischen Ägypten: Die Zeugnisse der verschiedenen Quellenarten

186 Yves MANNIEZ

Jouer dans l'au-delà ? Le mobilier ludique des sépultures de Gaule méridionale et de Corse ( $V^{\text {e }}$ siècle av. J.-C. - Ve siècle apr. J.-C.)

199 Mark Anthony HALL

Whose Game is it Anyway? Board and Dice Games as an Example of Cultural Transfer and Hybridity 


\title{
JOUER DANS L'AU-DELÀ ? \\ LE MOBILIER LUDIQUE DES SÉPULTURES DE GAULE MÉRIDIONALE ET DE CORSE (VE SIÈCLE AV. J.-C. - VE SIÈCLE APR. J.-C.)
}

\author{
Yves MANNIEZ \\ Archéologue chargé d'étude \\ Inrap Méditerranée (Nîmes) \\ UMR 5140 Archéologie des Sociétés Méditerranéennes \\ yves.manniez@inrap.fr
}

\section{RÉSUMÉ}

Parmi les objets déposés dans les sépultures de Gaule préromaine et romaine se trouve parfois du mobilier de jeu qui témoigne d'activités ludiques. Cette étude porte sur le territoire qui couvre la Narbonnaise, la Corse et le sud de la Lyonnaise. Nous avons tenté de recenser de manière exhaustive le mobilier de jeu retrouvé auprès des défunts et d'analyser les différents assemblages observés dans des contextes généralement bien datés. Nous avons aussi cherché à retrouver les courants culturels extra-régionaux, parfois anciens, à I'origine de dépôts particuliers. Si certains ensembles correspondent à la panoplie complète d'un ou de plusieurs joueurs, d'autres semblent avoir une valeur plus symbolique et pourraient témoigner de croyances et pratiques
MotS-CLÉs

Antiquité,

dés,

jetons,

mobilier de jeu,

pions,

pratiques funéraires,

protohistoire,

sépultures. funéraires qui ont varié d'une région à l'autre de l'Empire. Nous nous sommes aussi interrogés sur la signification de ces dépôts ludiques et sur les raisons de la disparition de ce mobilier dans les tombes de l'Antiquité tardive.
Among the objects deposited in graves, gaming devices evidence recreational activities. Our study covers Gallia Narbonnensis, Corsica and the South of Gallia Lugdunensis. We collected an exhaustive corpus of gaming material found with the deceased and we aim at analysing their set in usually well-dated contexts. We also aimed at defining extra-regional cultural trends, sometimes ancient, that may explain specific deposits. While some sets correspond to the complete panoply of one or more players, others seem to have more symbolic value and may reflect funerary beliefs and practices that could vary from one region to another of the Empire. We also investigate the function of these deposits and question the reasons of their disappearance from the graves of late Antiquity.

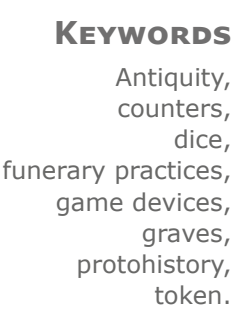




\section{INTRODUCTION}

Les tombes de Gaule préromaine et romaine livrent souvent des lots de mobilier. À côté de la vaisselle contenant les liquides et le repas funéraire offerts par les proches du défunt, on observe des objets de la vie quotidienne ayant appartenu ou non à la personne décédée. En fonction des périodes et des lieux, les dépôts sont plus ou moins abondants et plus ou moins variés. Ils renferment parfois des pièces de jeu ou, plus rarement, des jouets. En 1993, Michel Feugère a dressé un inventaire des éléments fréquemment retrouvés dans les sépultures de Gaule méridionale et consacré quelques lignes au mobilier ludique [1]. À la suite de ce travail et à la lumière des découvertes récentes, nous proposons ici de compléter le corpus sur un territoire un peu plus vaste qui correspond au quart sud-est du territoire actuel de la France et qui comprend I'ancienne province de Narbonnaise, la partie orientale de la Lyonnaise et la Corse (fig. 1) [2]. Les objets étudiés proviennent de sépultures, essentiellement à crémation, datant des $\mathrm{I}^{\mathrm{er}}, \mathrm{II}^{\mathrm{e}}$ et $\mathrm{III}^{\mathrm{e}}$ siècles apr. J.-C., mais nous avons aussi pris en compte quelques exemples plus rares attribués à la fin de la Protohistoire.

\section{[1] Feugère 1993, p. 149-150.}

[2] Nous remercions Alain Bouet qui a relu et corrigé cet article ainsi que les collègues et amis qui ont contribué à l'enrichissement de notre corpus, à l'illustration ou qui nous ont aidé dans notre recherche bibliographique : Valérie Bel, Chiara Bianchi, Marjorie Borios, Laurence Brissaud, Alice Dananai, Robert Gaday, Chérine Gébara, Sandra Jaeggi, Thierry Lejars, Yvon Lemoine, Annick Thuet, Laurent Vidal.

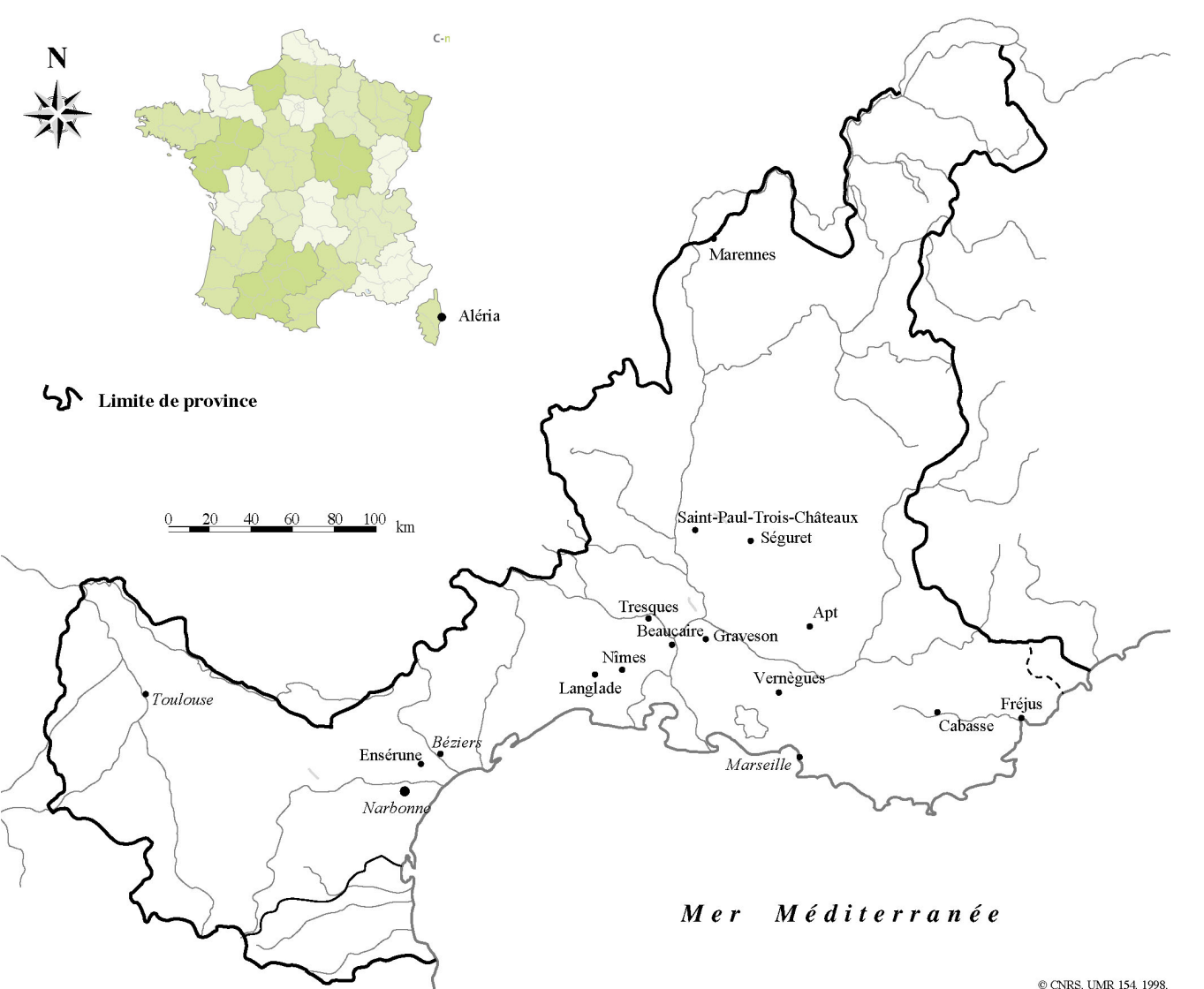




\section{LES DÉPÔTS DE JEU ET DE JOUETS EN CONTEXTE FUNÉRAIRE}

Des éléments de jeu semblent apparaître très tôt dans le mobilier des sépultures. Les plus anciennes dateraient du milieu du ve millénaire av. J.-C. (Néolithique). Deux osselets, un en os, l'autre en or, furent ainsi mis au jour dans une des nombreuses tombes de la nécropole de Varna en Bulgarie, fouillée entre 1972 et 1979 [3]. Pour François Poplin, il s'agit d'un des plus anciens témoignages de la sélection de ce petit os à des fins qui pourraient être ludiques [4]. Pour Jean-Marie Lhôte, ces deux objets constituent les plus anciennes pièces de jeu fabriquées par I'homme, mais un usage ludique n'est cependant pas assuré [5]. En Égypte ancienne, plusieurs plateaux de jeux ont été retrouvés en contexte funéraire ; la tombe de Toutankhamon (décédé vers 1327 av. J.-C.) renfermait ainsi plusieurs boîtes de jeu du Senet/20 cases avec des pions, osselets et bâtonnets de différentes matières dans leurs tiroirs [6]. La présence de plateaux de jeu et de pions et jetons est également bien attestée dans les tombes de Grèce classique et hellénistique [7]. Certaines catégories d'objets, comme les toupies et les osselets, semblent avoir été déposées de manière préférentielle dans les sépultures de jeunes sujets [8], mais l'identification de nombreux objets en tant que jouets au sens moderne reste débattue [9].

Toutes sortes de jouets en matière organique (balles de cuir, figurines de bois) étaient peut-être connus des peuples gaulois et ont pu disparaître sans laisser de traces. Leur absence dans les sépultures et d'autres contextes d'époque préromaine de notre zone d'étude suggère qu'ils aient été réalisés en matériau périssable.

\section{Figure 2}

Pions en pâte de verre de Pérouse. Photo d'après Diliberto et Lejars 2013, Figure 5.
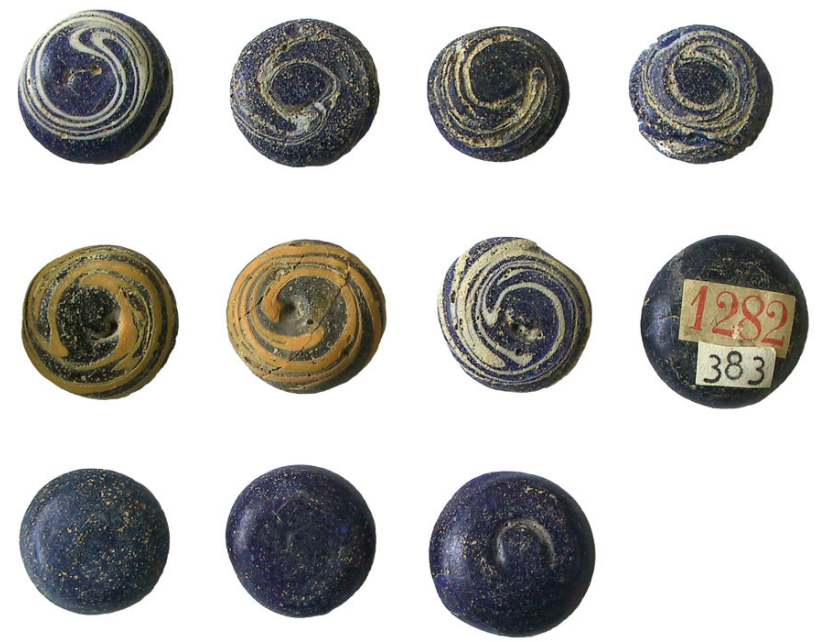

\section{LE MOBILIER DE JEU DES SÉPULTURES PRÉROMAINES}

Aucun des ensembles funéraires de la Gaule méditerranéenne de la période comprise entre le $\mathrm{III}^{\mathrm{e}}$ et le I $^{\text {er }}$ s. av. J.-C., recensés par Michel Py et Patrice Arcelin dans les années 1970-1980, ni aucune des tombes fouillées récemment à Nîmes et publiées sous la direction de Valérie Bel, y compris celles qui renfermaient du mobilier témoignant de la romanisation des populations locales [10], n'a livré d'objets similaires à ceux connus pour la même époque en Grèce. La seule exception est le site de Casabianda dans la commune d'Aléria, sur la côte est de la Corse. Cette nécropole utilisée entre le $v^{\mathrm{e}}$ et le $\mathrm{II}^{\mathrm{e}}$ siècle av. J.-C. a, en effet, fourni quelques pièces de jeu qui sont parmi les plus anciennes de l'aire géographique de notre étude [11].

\section{PIONS ET DÉS}

Des pions et dés proviennent de trois tombes différentes d'Aléria et témoignent, tout comme la céramique, d'influences très fortes avec la Grèce et l'Étrurie toute proche. Dans T 91 (vers 425 av. J.-C.) se trouvaient trois dés cubiques en os, dans T 102 (475 et 450 av. J.-C.), un seul exemplaire. Tous ces dés appartiennent à un module de grande taille, dont les côtés mesurent de 19 à $21 \mathrm{~mm}$. Ce module se retrouve en Gaule au début du I ${ }^{\text {er }}$ siècle apr. J.-C. [12], mais il sera vite délaissé au profit d'exemplaires de dimensions moyennes aux côtés de 10 à $15 \mathrm{~mm}$. Dans la sépulture T 148 (350 et 280 av. J.-C.), occupée en deux temps, deux dés en os plus petits étaient associés à treize pions en pierre et à quatre pions en pâte

[3] Whittle 1996, p. 100 (tombe n. 36) ; Poplin 1991, P. 41.

[4] POPLIN 1992, p. 46.

[5] LHÔTE 1999, p. 88. Sur la fonction des osselets en contexte divinatoire, voir par exemple l'article de Richard Ashton dans ce dossier.

[6] Desroches-Noblecourt 1966, p. 69. Sur les jeux égyptiens, voir l'article d'Anne Dunn-Vaturi dans ce dossier.

[7] Sur le matériel ludique de tombes de Grèce du nord, voir dans ce volume l'article de Despina Ignatiadou.

[8] DuRAND 1992 ; CARÈ 2010 ; CARÈ 2012 ; HASSELIN-ROUS 2013.

[9] Sur la poupée, DASEN 2011 ; DASEN 2012. Sur les miniatures qui ne sont pas nécessairement des dînettes destinées au jeu, ni spécifiquement aux enfant, LUCE 2011.

[10] BEL et al. 2008.

[11] Jehasse \& Jehasse $1973 ;$ Jehasse \& Jehasse 2001.

[12] Manniez 2010, p. 18. 

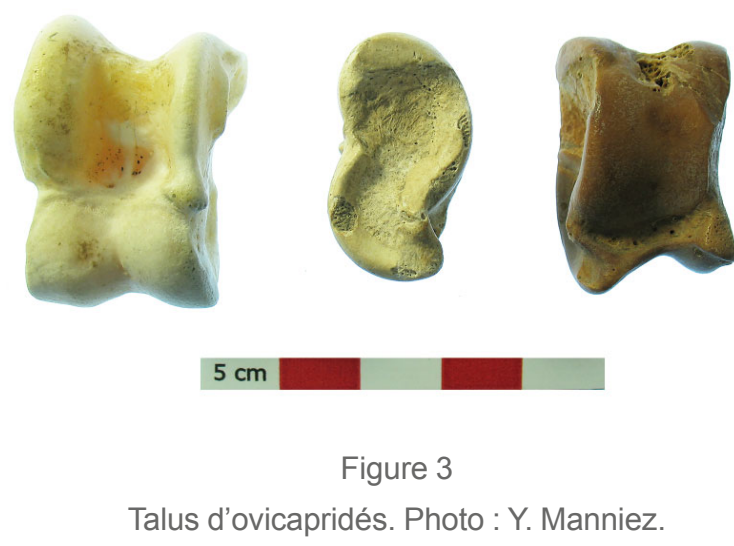

de verre. Il est intéressant de noter que deux des pions en pâte de verre présentent un décor spiralé. Ces pions à motif en spirale, d'origine italique, sont à rapprocher d'objets similaires découverts essentiellement dans des contextes funéraires des Marches et des régions littorales nord-adriatiques, en Toscane et en Ombrie (fig. 2). La plupart sont datés entre le milieu du IV ${ }^{\mathrm{e}}$ siècle et les premières décennies du III ${ }^{\mathrm{e}}$ siècle av. J.-C. [13].

\section{ASTRAGALES}

L'osselet, appelé astragalos en grec et talus en latin, est un petit os du tarse de la patte arrière d'ovicapridés (mouton, chèvre), qui se trouve aussi chez le cerf, le bœuf et même le porc (fig. 3). Les éléments de petite taille qui ont pu être utilisés dans des activités ludiques proviennent généralement d'ovicapridés. Les osselets ont servi à la fois de jeu d'adresse, particulièrement prisé des enfants et des jeunes filles, et de jeu de hasard, plutôt pratiqué par les hommes qui les utilisaient comme substitut du dé. Leur usage est également bien attesté comme matériel divinatoire [14].

Si les osselets sont relativement fréquents dans les sépultures grecques, où ils apparaissent souvent comme des marqueurs de tombes d'individus immatures [15], ce type d'objet est rarement présent dans les nécropoles préromaines du sud de la Gaule. Seules quatre incinérations d'Ensérune et deux sépultures d'Aléria en ont livré. À Ensérune, ce mobilier ne se trouve que dans les tombes de sujets immatures [16] ; la présence de perforations suggère cependant que plusieurs pièces ont pu servir de pendentif ou amulette. On retrouve des astragales percés dans la tombe, dite de chef, de Puech Maho à Sigean. Sur ce site, soixantedix-huit osselets étaient ainsi associés à d'autres amulettes pour former un collier [17]. À Aléria, une tombe datée du ve siècle av. J.-C. aurait livré une reproduction d'osselet en céramique attique, mais nous n'avons pas pu retrouver, ni de descriptif précis de cet ensemble, ni d'illustration concernant cet objet particulier [18]. La seconde tombe, une inhumation datée vers 155 av. J.-C., contenait quatre astragales ; la présence d'un fer de lance, de deux couteaux et d'un strigile suggère qu'il s'agit de celle d'un adulte de sexe masculin [19].

\section{LE MOBILIER DE JEU ET LES JOUETS DANS LES SÉPULTURES D'ÉPOQUE ROMAINE}

Dans notre corpus, basé sur un important catalogue de sépultures, nous n'en avons recensé qu'une trentaine, datées entre le $\mathrm{I}^{\text {er }}$ et le début du $\mathrm{III}^{\mathrm{e}}$ apr. J.-C., à avoir livré des jeux ou des jouets [20]. Cet examen a permis de constater que le petit mobilier ludique de I'aire continentale se retrouve presque exclusivement associé à des restes brûlés et qu'il concerne principalement des contextes de la seconde moitié du Ir siècle apr. J.-C. Une enquête menée au niveau du territoire national français montre que ce type de dépôt est rare, voire inexistant, dans les sépultures situées en dehors de notre zone d'étude [21]. Le plus grand nombre de cas se trouve concentré sur la bordure méditerranéenne, dans les régions placées sous l'influence des coutumes italiques, mais curieusement aussi dans les départements français de la Gaule Belgique [22] et dans la province romaine de Bretagne [23]. L'analyse détaillée des lots révèle une assez grande diversité dans les assemblages qui peuvent comprendre des pions en pâte de verre ou en pierre, des jetons et des tessères en os, des petits galets utilisés comme pièces de comptage, des dés et parfois une perle.

[13] DiliberTo \& LeJARS 2011, p. 443-445.

[14] SCHÄDLER 1996 ; NIKULINA \& SCHMÖLCKE 2008, p. 41-42; DASEN \& SCHÄDLER 2017.

[15] CARÈ 2010 ; CARÈ 2012.

[16] Tombe 53 : immature (plus ou moins 4 ans), 9 talus de mouton (un juvénile percé et 8 adultes), vers 300-275 av. J.-C. Tombe 84 : immature (4-6 ans), 24 talus de mouton, transition $\mathbf{V}^{\mathrm{e}}$-IV $\mathrm{s}$. av. J.-C. Tombe 167 : Infans I, 3 talus de mouton dont un perforé, vers 300-225 av. J.-C. Tombe 176 : Infans II (6-12 ans), 3 talus de mouton dont un percé, vers 250-225 av. J.-C, SchWALLER et al. à paraître.

[17] SOLIER 1968, p. 25-26, fig. 20.

[18] ]EHASSE 1980, p. 42.

[19] JeHASSE \& JeHASSE 1973, p. 231-235.

[20] En dépit de notre désir d'exhaustivité, il est probable que des lots aient échappé à notre enquête.

[21] FoulCheR 1984 ; GALLIOU 1989 ; BRIVES 2008.

[22] HANUT \& HENROTAY 2014.

[23] PHILPOTT 1991, p. 279. 


\section{LES DÉS EN OS OU IVOIRE}

Les dés en os, plus rarement en ivoire, peuvent être retrouvés seuls ou associés à des pions et des jetons. En Gaule méridionale, leur nombre varie entre un et six, mais les dépôts consistent d'ordinaire en un ou deux cubes. Ils furent parfois placés sur le bûcher au moment de la crémation du défunt, et on les retrouve brûlés, ou bien ils font partie du dépôt secondaire et ne présentent alors aucune trace de passage au feu.

Parmi les dés en ivoire, beaucoup plus rares, deux exemplaires proviennent l'un d'une incinération de Langlade (Gard) [24], I'autre de Graveson (Bouchedu-Rhône) [25]. Les dimensions des dés en os ou en ivoire varient généralement entre 10 et $15 \mathrm{~mm}$ de côté. Or dans un cas (SP1295 de l'avenue Jean-Jaurès à Nîmes), un dé de très petite taille, (entre 5,4 et $5,5 \mathrm{~mm}$ de côté), était déposé auprès du défunt d'âge indéterminé (adolescent ou adulte).

\section{LES PIONS EN PÂTE DE VERRE}

L'origine des pions en pâte de verre est ancienne, comme le montrent des tombes corses du IV ${ }^{e}$ siècle av. J.-C. [26] En Gaule méridionale, leur nombre varie entre cinq et vingt-six exemplaires par lot, comme dans la sépulture de Langlade (fig. 4) [27]. Il est intéressant de noter que ce chiffre est identique à celui des jetons de la tombe du médecin de Stanway, découverte en 1996 [28]. Les recherches d'Ulrich Schädler ont montré que ce mobilier correspond à celui de deux joueurs. Dans le matériel de Gaule méridionale, les

Figure 4

Mobilier de la tombe de Langlade. Photo d'après Feugère 2011, Figure 330. pièces se composent de deux couleurs différentes, généralement noire ou blanche. Des pions bleus ou gris sont aussi attestés, mais d'ordinaire en nombre plus réduit. Vingt-six pions proviennent d'une tombe de Nîmes [29], mais associés à un assemblage composite qui inclut deux pions en pierre et un jeton en os [30].

Le nombre vingt-six ne constitue cependant pas le maximum puisqu'une sépulture à incinération de Gloucester a livré trente-trois pions en pâte de verre et dix jetons en os [31]. Une autre sépulture, mise au jour à Amiens en 1895, renfermait un jeu composé de deux dés et de « 81 tessères » qui sont en fait des jetons en os et des pions en pâte de verre opaque [32]. La tombe de Tresques (Gard) a, elle, livré dix-huit pièces et demi de jeu dont six jetons en os et dix pions et demi en pâte de verre (trois noirs, un bleu clair, six blancs ou clairs et une moitié d'élément non précisé), ce qui ne permet pas de faire un partage égal, à moins de supposer qu'un joueur débutait sa partie avec six pions clairs en pâte de verre et l'autre avec six jetons en os. Georges Sudres, l'auteur de la fouille, propose de voir dans le nombre de dix-huit pièces et demie I'indication de l'âge du défunt [33].

[24] FEugÈre 2011, p. 395.

[25] GADAY 2009, p. 90.

[26] Sur les pions en pâte de verre en Grèce, voir dans ce volume I'article de Despina Igniatadou.

[27] FEUGÈRE 2011, p. 386.

[28] SCHÄDLER 2007, p. 365.

[29] FICHES \& VEYRAC 1996, p. 438, tombe 116.

[30] FiCHES \& VEYRAC 1996, p. 399.

[31] COOL 2008, p. 105.

[32] COLLOMBIER 1895-1897, p. 376.

[33] SUDRES 1981, p. 21-22.

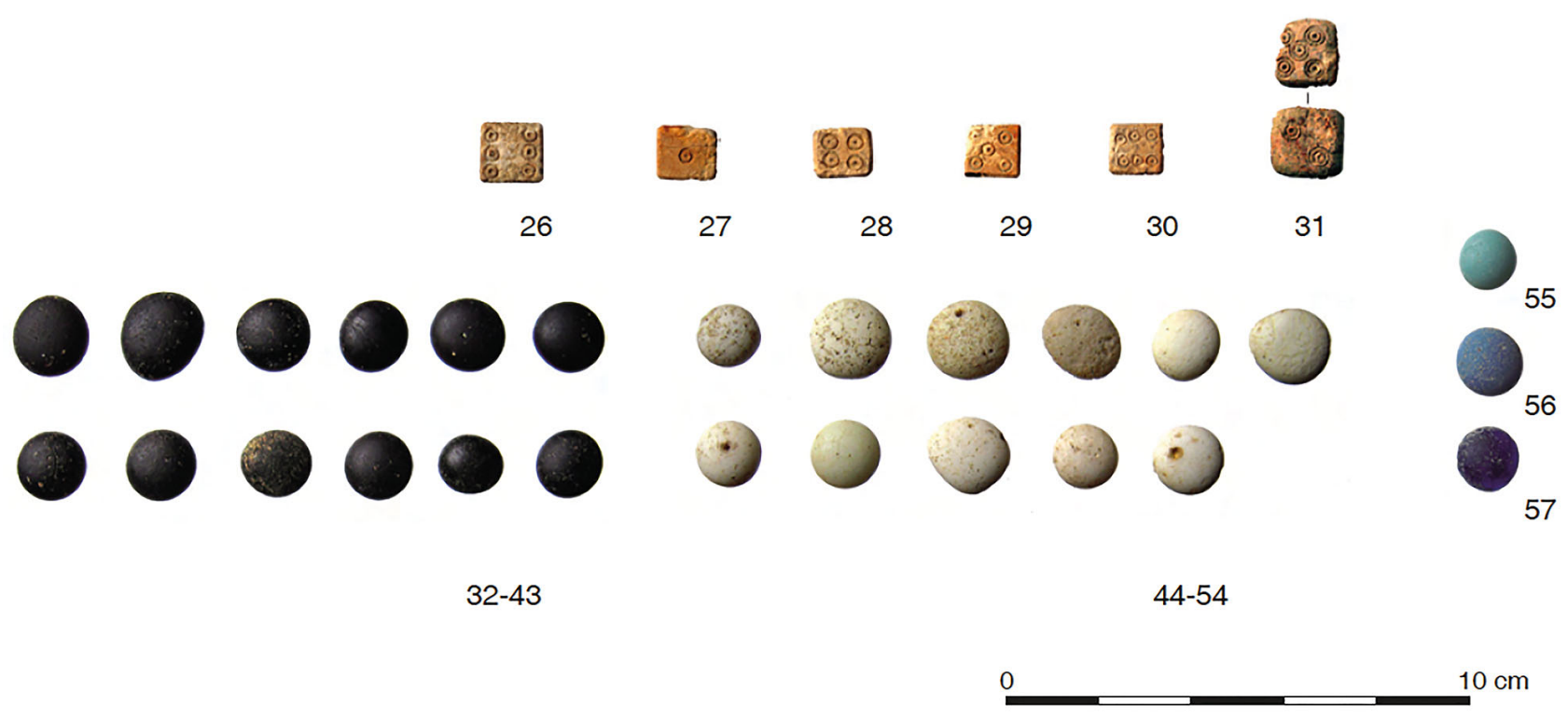



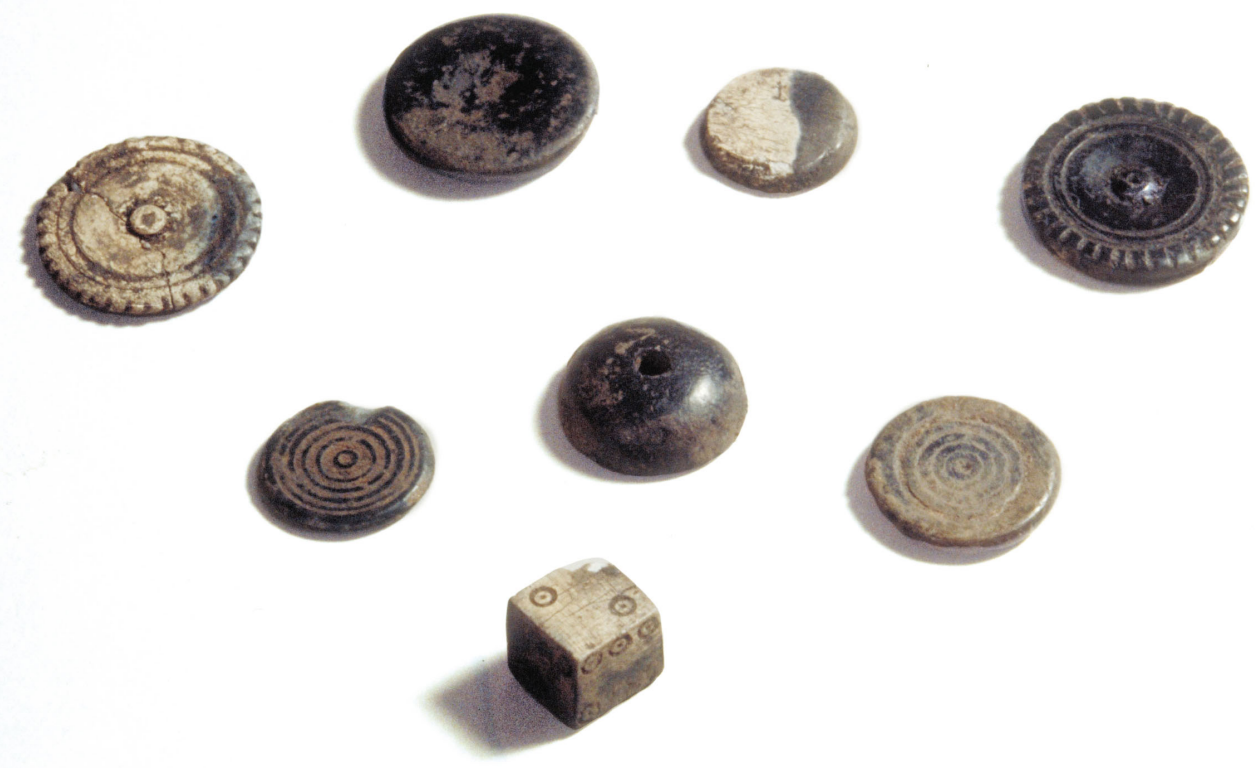

Figure 5

Jetons, dé et fusaïole en os de Fréjus.

Photo : Ph. Foliot.

\section{LES JetONS ET PIONS EN PIERRE}

Plusieurs tombes de Gaule méridionale renfermaient des jetons et pions en pierre, de simples petits galets naturels non travaillés. Dans la tombe du HautEmpire de la Guérine à Cabasse (Var), quinze de ces petites pierres plates semblent avoir représenté la mise du défunt. Un seul semble avoir été retaillé pour lui donner l'aspect d'un jeton en os [34]. Plus rarement, comme à Nîmes, on rencontre des objets reprenant la forme des pions en verre ou bien de demi-sphère [35].

\section{LES JETONS EN OS DANS LES DÉPÔTS DE CRÉMATION}

À l'instar des dés, et en fonction de leur origine (bûcher ou dépôt secondaire), les jetons en os peuvent être brûlés ou non. Ils sont soit lisses soit décorés de gorges concentriques. En Gaule du sud-est, leur nombre varie entre un et douze exemplaires par contexte funéraire.

Dans neuf cas, les jetons en os, sont seuls ou associés à des pions en pâte de verre dans des sépultures

[34] BÉRARD 1980, p. 34.

[35] FiCHES \& VEYRAC 1996, p. 399 (tombe 42).

[36] BÉRAUD et al. 1985, p. 32.

[37] BEL et al. 2002, p. 224-225 et 499.

[38] Tombes 164 et 178 de Saint-Paul-Trois-Châteaux, tombe 15 de Beaucaire : DEDET et al. 1978, p. 96 ;

MANNIEZ 1984, p. 45 et 133 ; Bel et al. 2002, p. 244 et 336 .

[39] CHAPOTAT 1978, p. 36.

[40] FEUGÈRE 1992.

[41] Feugère 1993, p. 151; Manniez 2016.

sans dé. Dans trois cas, ils sont associés à un ou deux dés. À Fréjus (Var), les six jetons semblent se répartir en deux lots à peu près similaires : deux lisses, deux à rainures concentriques et deux à bordure incisée (fig. 5) [36]. Il est intéressant de noter que, dans deux tombes de Saint-Paul-Trois-Châteaux (Drôme), on rencontre le même assemblage formé de douze jetons lisses et de deux décorés [37]. Cette valeur semble correspondre au nombre de pièces d'un joueur nécessaire pour pouvoir commencer une partie. Relevons que dans trois cas, à Saint-Paul-Trois-Châteaux et Beaucaire (Gard), les pièces considérées par les fouilleurs comme des jetons sont des disques moulurés de plus grand diamètre que les jetons ordinaires et qui rappellent davantage des couvercles de pyxides ou des tessères [38].

\section{LES JETONS EN OS DANS LES SÉPULTURES À INHUMATION}

L'unique sépulture à inhumation avec des jetons en os provient de Vienne (Isère). Cette tombe datée de la période 150-225 apr. J.-C. est la plus récente de notre corpus. Elle renfermait un lot de quatorze jetons en os (fig. 6-7) [39].

\section{LES PERLES}

Des perles sont parfois retrouvées en un seul exemplaire dans des sépultures. Elles appartiennent à deux catégories qui sont utilisées comme éléments de colliers : les perles côtelées en fritte bleu-vert, dite « en melon », et les exemplaires de type Kempten [40]. Les premières, fréquentes dans les tombes des nourrissons, ont probablement servi d'amulettes [41], 
les secondes, de porte-bonheur ou de fusaïoles [42]. L'hypothèse de talisman peut être aussi retenue lorsque ces perles sont retrouvées en petit nombre dans des lots de jetons ou de pions, comme c'est le cas à Séguret [43] (Vaucluse), à Cabasse [44] (Var) à Vernègues [45] (Bouches-du-Rhône) ou à Apt [46]

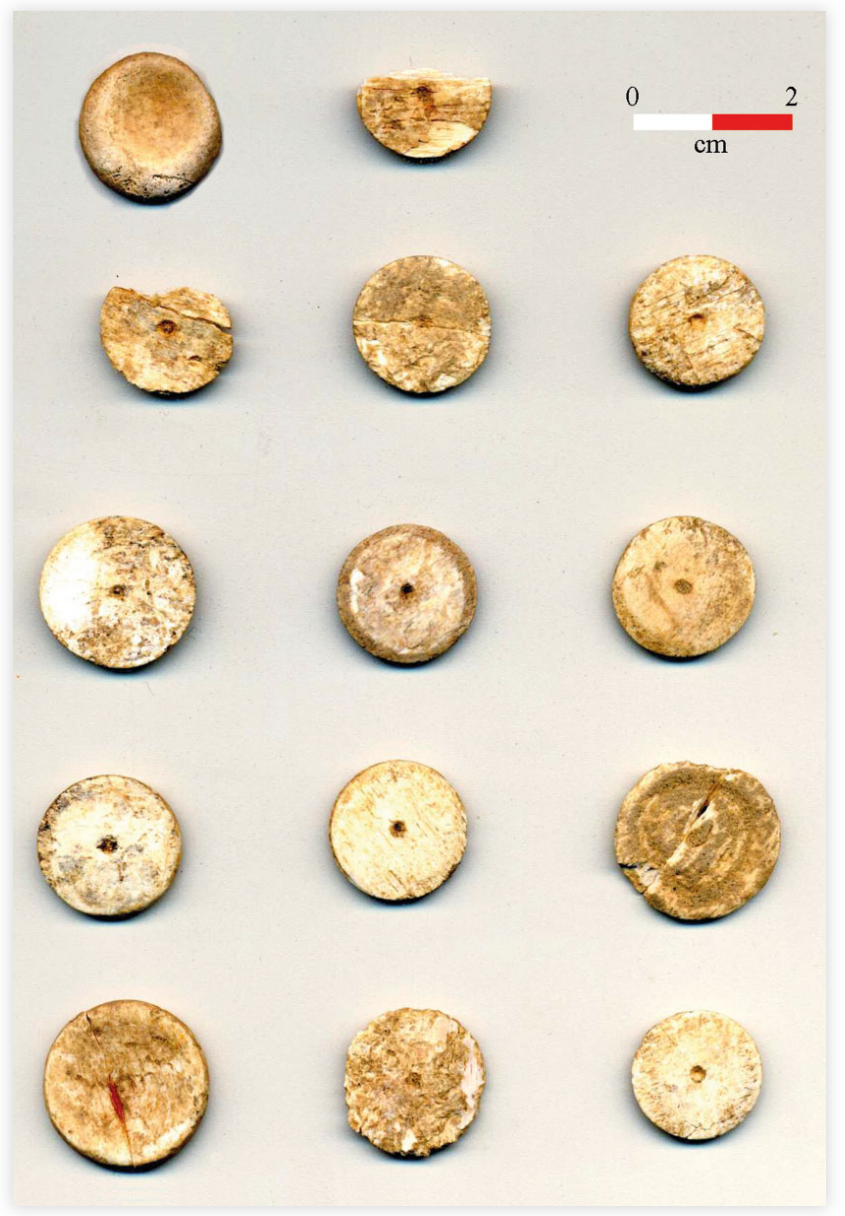

(Vaucluse), mais aussi, hors de notre zone d'étude, à Gloucester [47] (GB). Toutefois, I'association de treize perles en fritte côtelées et de onze pions en pâte de verre de différentes couleurs dans une tombe de Penteville (Cortil-Noirmont, Belgique) suggère qu'elles ont pu, dans certains cas, faire partie de la panoplie du joueur et être utilisées comme pièces d'action [48].

\section{LES ASTRAGALES}

En Gaule du sud, comme dans les provinces septentrionales, la présence d'astragales est extrêmement rare à l'époque romaine. Le seul site méridional à en avoir livré est celui de la Guérine à Cabasse. Dans cette nécropole, un exemplaire de talus se trouvait en place dans deux incinérations et en position remaniée dans une troisième, toutes trois datées du HautEmpire [49]. La présence d'un seul osselet dans chacun des lots rend moins plausible l'hypothèse d'un jeu de lancer, sans toutefois l'exclure. L'astragale pourrait être ici considéré comme un élément symbolique ou avoir une valeur d'amulette [50].

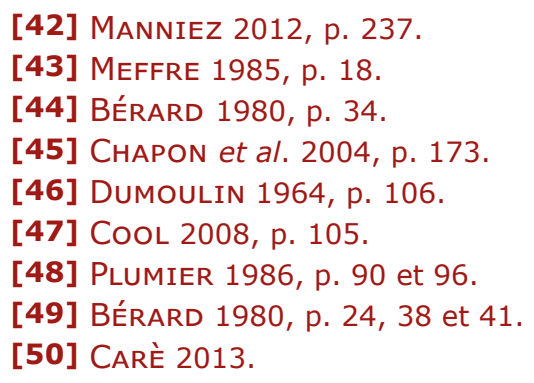

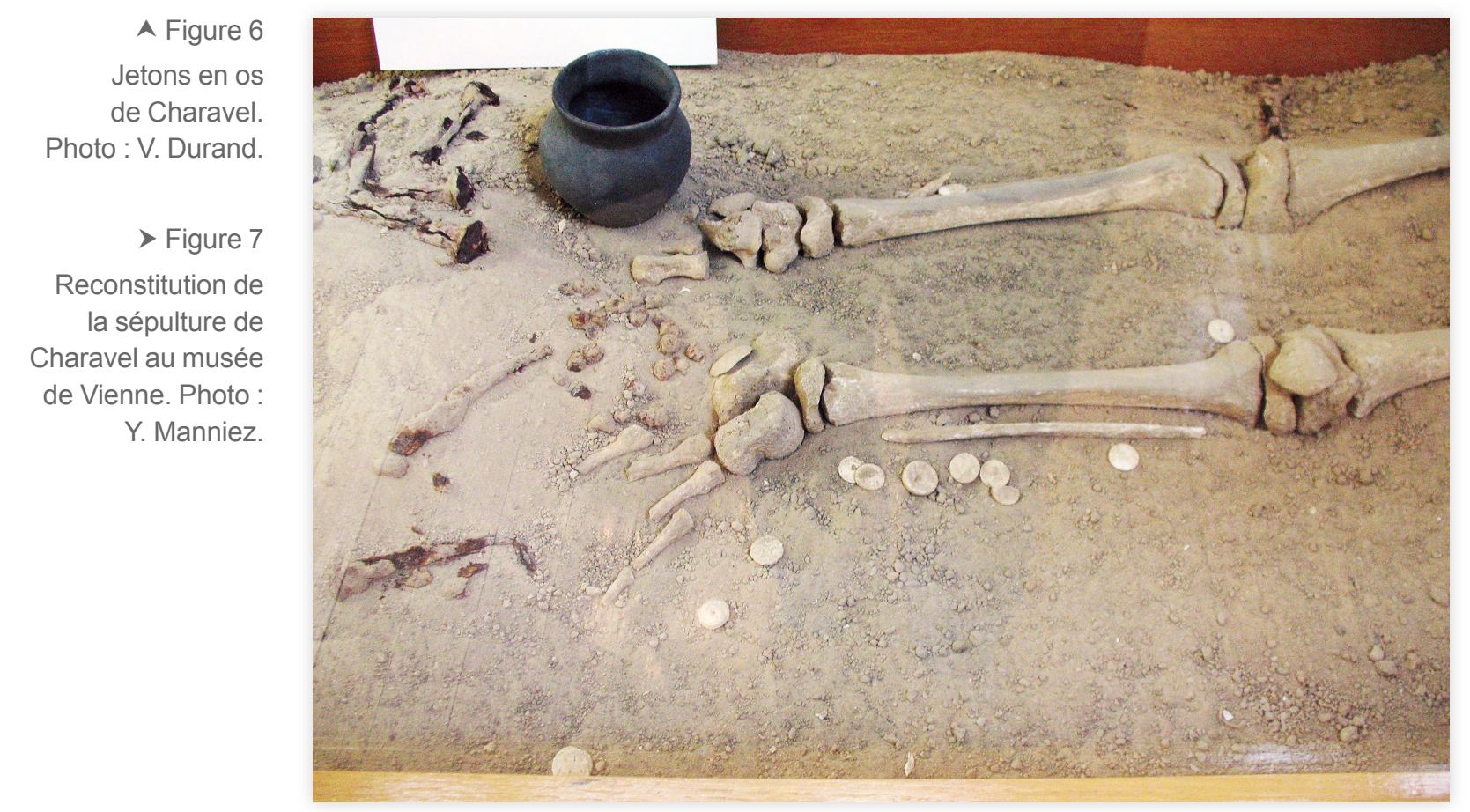




\section{LES JOUETS ET FIGURINES}

Le dépôt de jouets est inhabituel et le nombre de sépultures livrant ce type de mobilier très rare. Nous n'avons pu en répertorier que trois cas. Le premier est un dépôt de crémation datable de la fin du $\mathrm{I}^{\mathrm{er}}$ siècle av. J.-C. mis au jour à Nîmes en 1884 et dont le mobilier semble avoir été perdu. Il a livré plusieurs vases en terre cuite, dont une cruche à tubulure latérale considérée comme un biberon, souvent associée aux sépultures d'enfant, et une poupée en terre cuite

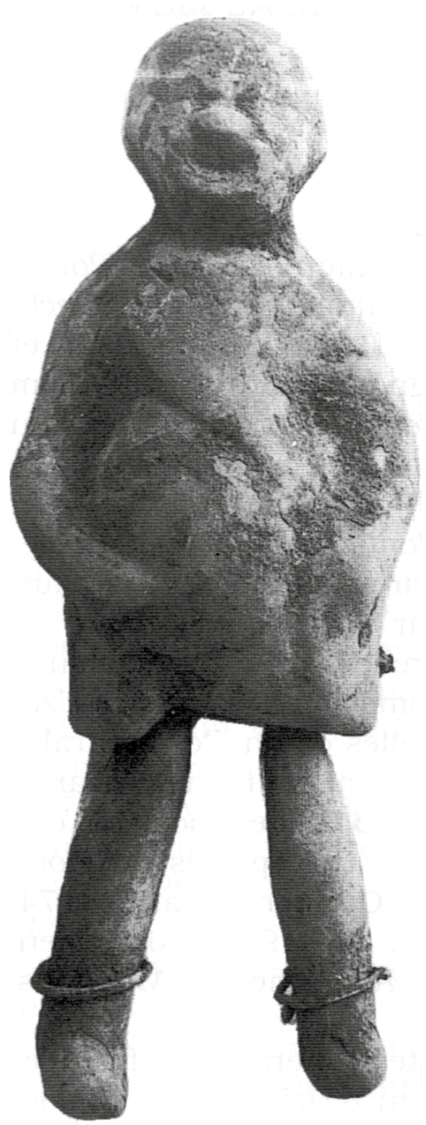

$<$ Figure 8 :

Poupée en terre cuite de Nîmes. Photo d'après

Fiches et Veyrac 1996, Figure 362

$>$ Figure 9

Figurine en terre cuite de Quissac. Photo : D. Travier.

$\checkmark$ Figure 10

Figurines en terre cuite de Marennes. Photo d'après Bel 2012, Figure 10 (fig. 8). Cette poupée, dont nous n'avons pas de mesures, présentait des jambes articulées et deux sortes de petits bracelets en bronze au niveau des chevilles [51].

Le deuxième ensemble, probablement à crémation, a été mis au jour à Quissac, dans la région nîmoise. Cette sépulture a livré une figurine en terre cuite représentant un oiseau (fig. 9), ainsi qu'un petit pendentif ou amulette en or en forme de massue [52]. Un bûcher funéraire du site de Saint-Fréjus à Marennes (Rhône) contenait, quant à lui, divers objets dont quatre figurines en terre cuite (trois colombes et un coq) et neuf pions (cinq en verre et quatre en os) et là, encore, un pendentif en or comparable au précédent (fig. 10) [53]. L'étude des os a permis de savoir que le sujet était un enfant de deux à cinq ans.

[51] FiChes \& VEYRAC 1996, p. 472.

[52] PRovost 1999, p. 529.

[53] BEL 1998, p. 42 ; BeL 2012, p. 213.

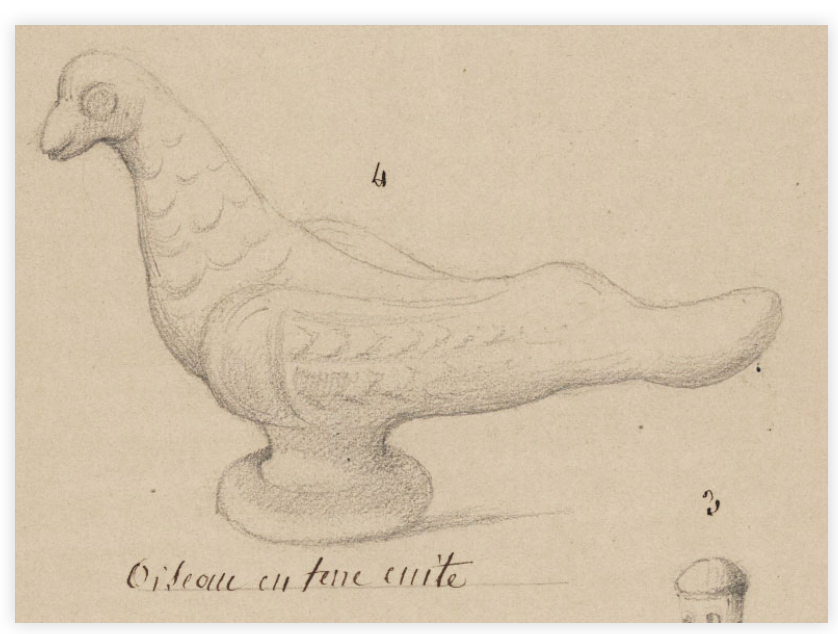

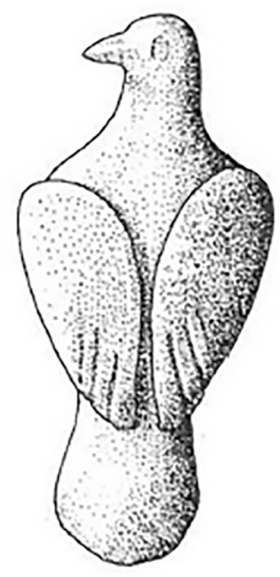
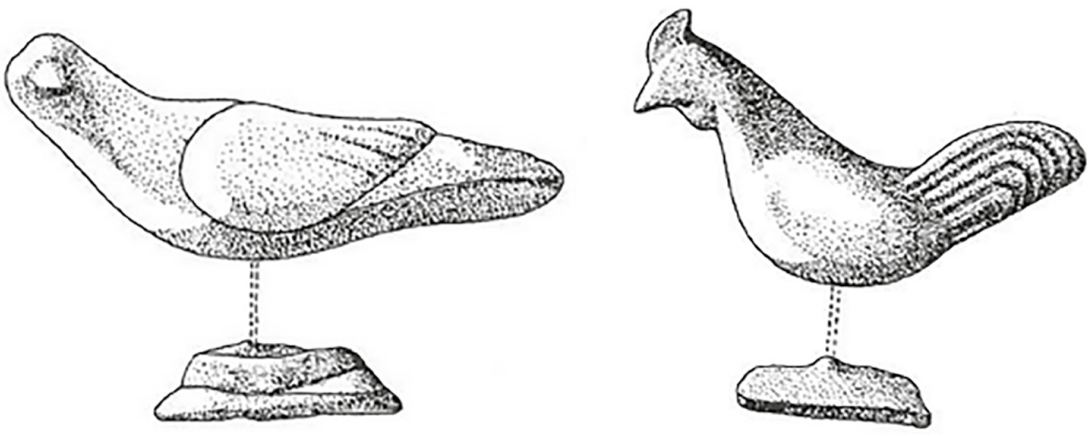

0 $5 \mathrm{~cm}$
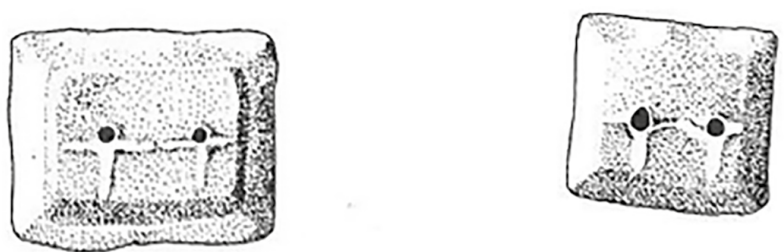
Figure 11

Tableau synthétique des pièces de jeu trouvées dans les sépultures du sud-est de la Gaule. DAO : Y. Manniez.

\begin{tabular}{|c|c|c|c|c|c|c|c|c|c|c|c|c|}
\hline (en italique : inhumation) & sujet & datation & (9)ton décoré & 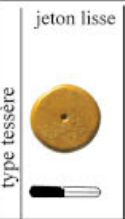 & $\begin{array}{c}\text { pion } \\
\text { pâte de verre }\end{array}$ & $\begin{array}{c}\text { pion } \\
\text { spiralé } \\
\text { (3) }\end{array}$ & 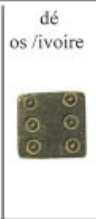 & astragale & pion en pierre & 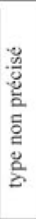 & petit galet & perle \\
\hline Aléria T91 & $?$ & v. 425 & & & & & 3 & & & & & \\
\hline Aléria T102 & $?$ & $475-450$ & & & & & 1 & & & & & \\
\hline Aléria T148 & $?$ & $350-280$ & & & 1 & 3 & 2 & & & 13 & & \\
\hline Béziers, Kléber SP2050 & $?$ & $1-100$ & & & & & $1^{*}$ & & & & & \\
\hline Béziers, Kléber SP2078 & $?$ & $1-150$ & & $1^{*}$ & 1 & & & & & & & \\
\hline Langlade, Vignaud SP105 & adulte? & $75-125$ & & & 26 & & 6 & & & & & \\
\hline Nîmes, Jaurès/Républ. & femme & $75-125$ & & 1 & 23 & & & & & & 2 & \\
\hline Nîmes, rte de Beaucaire & enfant? & $50-250$ & 2 & & & & 1 & & 3 & & & \\
\hline Nîmes, 78 JJ SP1295 & adulte & $150-200$ & & & & & 1 & & & & & \\
\hline Nîmes, 78 JJ SP1362 & nouv-né & $100-200$ & & & & & & & & & 2 & 1 \\
\hline Tresques, Courac T6 & adulte? & $40-110$ & & 6 & 10,5 & & 2 & & & 2 & & \\
\hline Beaucaire, Marronniers T15 & femme & $50-100$ & 1 & 1 & 5 & & & & & & & \\
\hline Graveson, Sagnon & femme? & $50-100$ & & & 22 & & 1 & & & & & \\
\hline Saint-Paul, Valladas T22 & adulte & $60-100$ & & & & & $1^{*}$ & & & & & \\
\hline Saint-Paul, Valladas T32 & adulte & $60-100$ & & 1 & & & & & & & & \\
\hline Saint-Paul, Valladas T78 & adulte & $70-200$ & & & & & $1^{*}$ & & & & & \\
\hline Saint-Paul, Valladas T45 & $?$ & $15-70$ & $2 *$ & $12 *$ & & & & & & & & \\
\hline Saint-Paul, Valladas T164 & adulte & $15-70$ & & $1^{*}$ & & & & & & & & \\
\hline Saint-Paul, Valladas T178 & $?$ & $60-100$ & & $1^{*}$ & & & & & & & & \\
\hline Saint-Paul, Valladas T269 & enfant & $70-150$ & & & & & $1^{*}$ & & & & & \\
\hline Saint-Paul, Valladas T276 & $?$ & $70-200$ & $2 *$ & $12^{*}$ & & & & & & & & \\
\hline Séguret, Les Sausses T1 & & $70-100$ & & 3 & 2 & & & & & & & 1 \\
\hline Apt, Saint-Lazare T33 & $?$ & $50-100$ & 3 & 3 & & & & 1 & & & & 1 \\
\hline Apt, Saint-Lazare 1955 & $?$ & $50-250$ & & & 9 & & 2 & & & & & \\
\hline Cabasse, Guérine T13 & $?$ & $50-100$ & & & & & & & & & 15 & \\
\hline Fréjus, Pauvadou T159 & $?$ & $50-100$ & $5^{*}$ & $1^{*}$ & & & $1^{*}$ & & & & & \\
\hline Marennes, Saint-Fréjus 6100 & enfant & $50-100$ & & 4 & 5 & & & & & & & \\
\hline Vernègues, F41 & $?$ & $100-200$ & 6 & 3 & & & & & & & & 2 \\
\hline \multirow[t]{2}{*}{ Vienne, Charavel T2 } & adulte & $150-225$ & & 14 & & & & & & & & \\
\hline & & & $*$ : obj & et brûlé & & & & & & & & \\
\hline
\end{tabular}




\section{BILAN}

À partir des informations recueillies dans le cadre de cette étude, nous avons réalisé un tableau synthétique qui permet d'avoir une représentation globale des différents assemblages d'objets ludiques mis au jour dans les sépultures du sud-est de la Gaule (fig. 11). L'examen de ce tableau met en lumière les deux grandes périodes chronologiques qui sont concernées par du mobilier de jeu, la période préromaine, représentée par les tombes d'Aléria, et le Haut-Empire.

Il révèle quelques particularités propres à chaque catégorie d'objets. Ainsi, les pions en pâte de verre que l'on retrouve souvent en grand nombre et qui permettent probablement de repérer les panoplies de joueurs sont, à l'instar des dés creux, les pièces les plus anciennes associées aux défunts. Les pions à décor spiralés qui apparaissent, comme les modèles simples, dans les sépultures du IV ${ }^{\mathrm{e}}$ siècle av. J.-C. des nécropoles de Toscane et d'Ombrie, n'ont pas connu de pérennité à l'époque romaine. En effet, les exemplaires du Haut-Empire de Gaule méridionale sont tous dépourvus de décor. À une exception près, la tombe de Marennes, on note qu'ils ont toujours été placés en dépôt secondaire et n'ont, de ce fait, jamais été brûlés. Dans les lots importants comprenant un nombre inégal de pièces (fig. 12), la présence d'éléments de trois couleurs différentes amène à s'interroger sur les types de jeu auxquels ces pions devaient appartenir.

Pour ce qui concerne les dés, on observe que les types anciens de grand module ( $20 \mathrm{~mm}$ de côté) ont très vite été abandonnés au profit des cubes de taille moyenne. Les dés miniatures de $5 \mathrm{~mm}$ de côté, qui semblent être une spécificité nîmoise et qui sont plus fréquents sur les sites d'habitat, ne sont représentés

Figure 12

Pions de la tombe de Graveson. Photo : Y. Manniez.

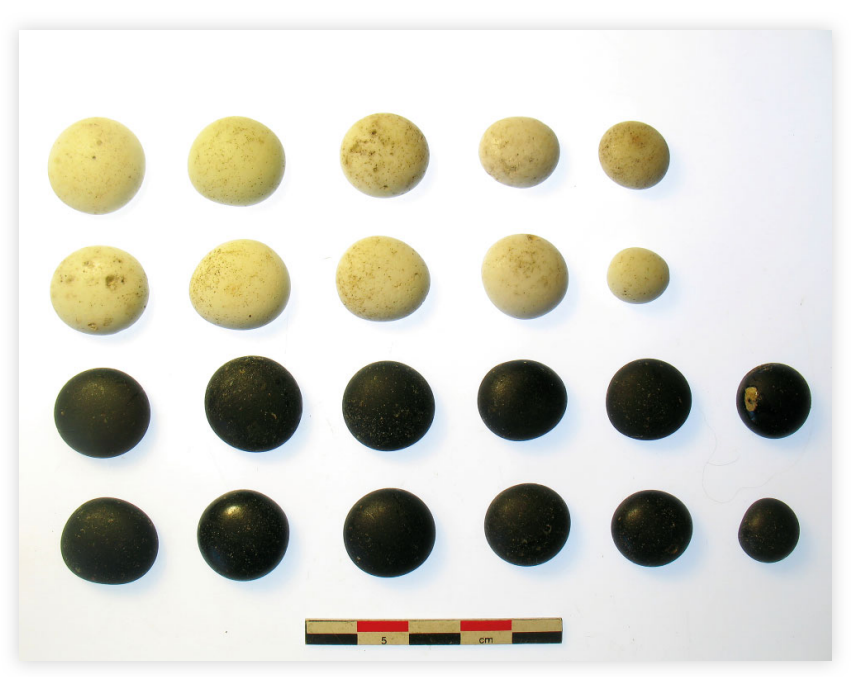

que dans une sépulture. Il est toutefois intéressant de signaler la découverte d'un lot de quatre exemplaires de ce type dans un petit trésor du début du III ${ }^{\mathrm{e}}$ siècle apr. J.-C. appartenant certainement à un joueur et qui comprenait aussi trois bagues en argent, deux intailles et 43 deniers [54]. Le mobilier précieux et les monnaies associés aux quatre dés, probablement utilisés ici pour des jeux de hasard, devaient correspondre soit aux gains, soit à la mise de ce personnage. Quant aux jetons en os, on remarque qu'ils sont absents des tombes les plus anciennes. Les informations recueillies sur les sites d'habitat permettent de situer leur apparition en Gaule du sud vers le milieu du $\mathrm{I}^{\text {er }}$ siècle apr. J.-C. Notons que les trois lots les plus importants issus des sépultures étudiées concernent des objets intacts. On peut donc supposer que les jetons brûlés recueillis dans les tombes à crémation ne représentent parfois qu'une partie des pièces déposées sur le bûcher.

\section{EN CONCLUSION...}

Pour tenter de répondre à la question sur la signification du mobilier ludique en contexte funéraire, qui sert de titre à notre communication, rappelons combien il est difficile de percevoir le sens exact des gestes qui ont conduit au dépôt d'objets ludiques, tout comme à celui d'autres objets dans les sépultures de l'Antiquité. La grande variété des lots et des pratiques ainsi que l'absence d'écrits sur le sujet nous amènent à échafauder des hypothèses, mais les incertitudes demeurent. Dans les rares sépultures préromaines étudiées ici, il convient de distinguer les véritables pièces de jeu des astragales dont la présence est sujette à diverses interprétations. Les dés en os ou en ivoire et les pions en pâte de verre des tombes d'Aléria témoignent, via I'Italie du Nord, de pratiques culturelles du monde grec qui ont concerné à la fois les vivants et les morts. Ce mobilier annonce, avant I'heure, des coutumes funéraires imitées cette fois du monde romain qui auront cours durant le Haut-Empire. Les osselets de Corse, de Sigean ou d'Ensérune, comme ceux des ensembles funéraires anciens de Grande Grèce étudiés par Barbara Carè, ne sont pas forcément des marqueurs ludiques. Il est possible de les interpréter comme les vecteurs de pratiques magiques destinées à protéger le mort [55]. Le mobilier de jeu d'époque romaine, beaucoup plus abondant, ne fait son apparition dans les sépultures de

[54] MANNIEZ 2010, p. 19.

[55] CARÈ 2010, p. 462-463. 
Gaule du Sud que dans le courant du I ${ }^{\text {er }}$ siècle apr. J.-C. En fonction du nombre de pions en pâte de verre ou de jetons en os, de leur état de conservation, on peut être tenté d'y reconnaître des éléments qui formaient la panoplie d'un, voire de deux joueurs. Cette remarque concerne surtout les lots importants d'objets. Quel sens prennent-ils dans la tombe ? Étaient-ils placés avec le défunt pour qu'il puisse les utiliser dans ce qui correspond à notre au-delà, ou simplement en mémoire des moments heureux qu'il ou elle avait partagé ici-bas ? Les pièces se rapportent à des jeux qu'il n'est pas facile d'identifier car ils ne sont pas décrits en détail dans la littérature ancienne. Une large gamme de possibilités peut être envisagée : latrunculi, jeu des douze points (variante de nos backgammon ou tric-trac), petite marelle, ou jeu de moulin, pour les plateaux recevant des pions et jetons ; parties de dés diverses ne nécessitant pas de pions pour des jeux de hasard, mais avec mise d'argent ou d'objets précieux.

Lorsque le mobilier est brûlé sur le bûcher, la finalité du dépôt est-elle différente ? On a peut-être offert au défunt les jetons et dés qui lui appartenaient. Cependant nous ignorons si ces objets étaient considérés comme définitivement détruits ou si I'on croyait qu'ils avaient, eux aussi, une nouvelle vie dans I'au-delà [56].

Dans le cas des pièces de jeu isolées ou placées en petit nombre dans les dépôts secondaires, c'est-à-dire non brûlés, leur présence est peut-être plus symbolique. On peut en effet se demander s'il ne s'agit pas de l'offrande déposée par un proche, d'un moyen de conjurer les mauvais sorts et de rappeler la fragilité de l'existence.

Il est probable que les rares jouets issus des contextes funéraires étaient initialement destinés à divertir les jeunes défunts. Leur présence dans la tombe peut être symbolique, mais il peut simplement s'agir du bien appartenant au jeune défunt ou le témoignage de l'affection portée par les proches. Même si les preuves matérielles manquent, on ne peut exclure que cette rareté soit liée à la disparition des jouets en matériaux périssables, comme le bois ou le tissu.

Les figurines de terre cuite, notamment lorsqu'elles sont retrouvées dans les tombes d'immatures, ne peuvent toutefois pas être considérées comme des jouets. Elles ont probablement eu un rôle prophylactique. Dans celles des sujets plus âgés, leur présence n'est pas clairement définie : reproductions en terre cuite d'animaux de la ferme ou destinés aux sacrifices, substituts d'animaux de compagnie [57] ? Pour ce qui est de la caractérisation des défunts du Haut-Empire, nous ne pensons pas que la présence de tel ou tel assemblage de pièces de jeu soit le révélateur d'un statut social particulier. Il semblerait toutefois que les lots importants associant pions en pâte de verre et dés se retrouvent principalement dans des sépultures en coffre livrant un mobilier de valeur. La caractérisation sexuelle semble délicate car les pièces ludiques proviennent souvent de crémations et elles ne sont pas forcément associées à des mobiliers discriminants.

Il est intéressant de noter que, dans la région étudiée, le mobilier de jeu ne se retrouve plus dans les contextes funéraires du Bas-Empire, qui livrent pourtant encore différents types d'offrande, ni dans les tombes du haut Moyen Âge [58]. Si le mobilier livré par les tombes d'Aléria, notamment les céramiques attiques, laisse croire qu'elles sont celles de colons de culture gréco-italique, celui des sépultures de Gaule méridionale, dans sa grande majorité, témoigne simplement d'un phénomène d'acculturation qui s'amplifie au milieu du $\mathrm{I}^{\mathrm{er}}$ siècle apr. J.-C. et qui se traduit par I'adoption du mode de vie italique et par un important développement de l'instrumentum.

Le mobilier de jeu mis au jour dans les sépultures apparaît finalement comme l'indicateur de pratiques culturelles et sociales héritées du monde grec et qui ont touché à des degrés différents la plupart des régions de l'Empire romain. Ces dernières semblent s'être principalement développées sur la bordure méditerranéenne de la Gaule et sur le tracé probable des axes commerciaux desservant les provinces septentrionales.

[56] Hypothèse émise par Roberte Hamayon le 21 mai 2014, lors de sa conférence intitulée « Un regard d'anthropologue à la lumière des quatre "principes du jeu" de Roger Caillois » lors du colloque à La-Tour-dePeilz (Suisse). Voir aussi U. Harva, Les représentations religieuses des peuples altaïques, Paris : Gallimard, 1959 , p. 215.

[57] DASEN 2011, p. 55; DASEN 2012.

[58] MANNIEZ 1999. 
ARCelin, Patrice, 1979, «La nécropole préromaine de l'Arcoule, commune du Paradou (B.-du-Rh.) 》, Documents d'Archéologie Méridionale 2, p. 133-156.

Arcelin, Patrice \& Arcelin, Charlette, 1975, « Les sépultures préromaines de Saint-Rémy-de-Provence (B.-du-Rh.) », Revue Archéologique de Narbonnaise 8, p. 67-135.

BEL, Valérie, 1998, L'ensemble funéraire du Haut-Empire du site de Saint-Fréjus à Marennes (Rhône). Travaux d'archéologie préventive sur le tracé de l'autoroute A6. Archives du Service régional de l'Archéologie de Rhône-Alpes.

BEL, Valérie et al., 2002, Pratiques funéraires du Haut-Empire dans le Midi de la Gaule. La nécropole gallo-romaine du Valladas à Saint-Paul-Trois-Châteaux (Drôme), Lattes (Monographies d'Archéologie Méditerranéennes 11).

BEL, Valérie, 2012, « Les dépôts de mobilier dans les tombes d'enfants et d'adolescents en Gaule Narbonnaise au Haut-Empire », dans Antoine Hermary \& Céline Dubois (éd.), L'enfant et la mort dans l'Antiquité, III. Le matériel associé aux tombes d'enfants, Paris, p. 193-216.

BEL, Valérie et al., 2008, Tombes et espaces funéraires de la fin de l'âge du Fer et du début de l'époque romaine à Nîmes, Lattes (Monographies d'Archéologie Méditerranéenne 24).

BEL, Valérie et al., 2016, Deux ensembles funéraires d'époque romaine, avenue Jean-Jaurès à Nîmes (Gard), Revue Archéologique de Narbonnaise, Supplément 46.

BÉRARD, Georges, 1980, «La nécropole de La Guérine à Cabasse (Var) », Revue Archéologique de Narbonnaise 13, p. $19-63$. BÉRAUD, Isabelle et al., 1985, Les nécropoles gallo-romaines de Fréjus. Trois années d'action du service archéologique départemental, Saint-Raphaël.

BrIVes, Anne-Laure, 2008, Sépultures et société en Aquitaine romaine : étude de la fonction du mobilier métallique et du petit mobilier à partir des ensembles funéraires ( $I^{e r}$ S. av. J.-C. - début IVe s. ap. J.-C.). Thèse de doctorat inédite sous la direction de Francis Tassaux. Université Michel de Montaigne, Bordeaux III.

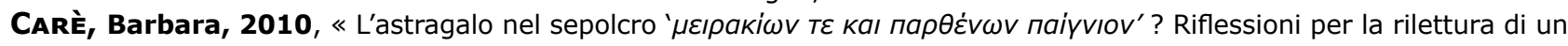
costume funerario: i casi di Locri e Caulonia », dans Lucia Lepore \& Paola Turi (éd.), Caulonia tra Crotone e Locri 2, Atti del Convegno Internazionale, Firenze, 30 maggio - 1 giugno 2007, Firenze, p. 459-467.

CARÈ, Barbara, 2012, «L'astragalo in tomba nel mondo greco: un indicatore infantile ? Vecchi problemi e nuove osservazioni a proposito di un aspetto del costume funerario », dans Antoine Hermary \& Céline Dubois (éd.), L'enfant et la mort dans I'Antiquité, III, Le matériel associé aux tombes d'enfants, Paris, p. 403-416.

CARÈ, Barbara, 2013, « Le symbolisme des astragales », Archéothéma 31, p. 56.

Chapon, Philippe et al., 2004, « Les nécropoles de Vernègues. Deux ensembles funéraires du Haut-Empire à la périphérie d'une agglomération secondaire », Revue Archéologique de Narbonnaise 37, p. 109-209.

Снapotat, Gabriel, 1978, «La nécropole gallo-romaine de Charavel à Vienne (Isère) », Nouvelles Archives du Muséum d'Histoire naturelle de Lyon, suppl. 16, p. 35-43.

Collombier, Félix, 1895-1897, « Note sur un flacon gallo-romain en verre », Bulletin de la Société Archéologique de Picardie 19, p. 376-382.

Cool, Hilary, 2008, « The Small Finds » dans Andy Simmonds \& Nicholas Márquez-Grant \& Louise Loe, Life and Death in a Roman City, Oxford (Oxford Archaeology Monograph 6), p. 104-115.

DASEN, Véronique, 2011, «De la Grèce à Rome : Des jouets pour grandir ? » dans Dorothée Charles \& Bruno Girveau (éd.), Des jouets et des hommes, Paris, p. 53-59.

DASEN, Véronique, 2012, « Cherchez l'enfant ! La question de l'identité à partir du matériel funéraire », dans Antoine Hermary \& Céline Dubois (éd.), L'enfant et la mort dans l'Antiquité, III, Le matériel associé aux tombes d'enfants, Paris, p. 9-22.

DASEN, Véronique \& SCHÄDLER, Ulrich, 2017, « Jeu et divination. Un nouveau témoignage de l'époque romaine », Archeologia, 553, p. 60-65.

DEDET, Bernard et al., 1978, Ugernum, protohistoire de Beaucaire, Association pour la recherche archéologique en Languedoc oriental 6, Caveirac.

Desroches-Noblecourt, Christiane, 1966, Toutankhamon, vie et mort d'un pharaon, Paris.

Diliberto, Manuela \& Lejars, Thierry, 2013, « Un cas de mobilité individuelle aux IVe et III ${ }^{\mathrm{e}}$ s. av. J.-C. : I'exemple des pièces de jeu d'origine italique », dans Anne Colin \& Florence Verdin (éd.), L'âge du Fer en Aquitaine et sur ses marges. Mobilité des hommes, diffusion des idées, circulation des biens dans l'espace européen à l'âge du Fer. Actes du $35^{\circ}$ Colloque international de I'AFEAF (Bordeaux, 2-5 juin 2011), Bordeaux.

Dumoulin, André, 1964, « Découverte d'une nécropole gallo-romaine à Apt (Vaucluse) », Gallia 22, p. 87-110.

DuRAND, Agnès, 1992, « Jeux et jouets de l'enfance en Grèce et à Rome », Les Dossiers de l'Archéologie 168, p. 10-17. FeUGÈRE, Michel, 1992, «Les perles de type Kempten en Gaule méridionale », Archéologie en Languedoc 16, p. 149-148. FeUGÈRE, Michel, 1993, « L'évolution du mobilier non céramique dans les sépultures de Gaule méridionale (II ${ }^{\mathrm{e}}$ siècle av. J.-C. - début du ve siècle ap. J.-C.) », dans Manuela Struck (éd.), Römerzeitliche Gräber als Quellen zu Religion, Bevölkerungsstruktur und Sozialgeschichte, Mainz, p. 119-165. 
FeUGère, Michel, 2011, «Le mobilier du mausolée romain » dans Chris Hayden \& Juliette Michel (éd.), Le Vignaud 3, Langlade (Gard), II, Occupation funéraire antique, Rapport final de fouille archéologique, Service Régional de l'Archéologie de Languedoc-Roussillon, Oxford Archéologie Méditerranée, Montpellier, p. 383-405.

Fiches, Jean-Luc \& Veyrac, Alain (éd.), 1996, Nîmes, Carte Archéologique de la Gaule, 30/1, Pré-inventaire archéologique sous la dir. de Michel Provost, Paris.

Foulcher, Christine, 1984, Les rites funéraires du I er au III ${ }^{e}$ s. ap. J.-C. dans le Midi de la Gaule d'après l'étude des sépultures, Mémoire de maîtrise inédit, Université de Toulouse-Le Mirail.

GADAY, Robert et al, 2009, Sagnon à Graveson (Bouches-du-Rhône), Rapport final de diagnostic archéologique, Service Régional de l'Archéologie de Provence-Alpes-Côte d'Azur, Éguilles.

Gallioque, Patrick, 1989, Les tombes romaines d'Armorique. Essai de sociologie et d'économie de la mort, Documents d'Archéologie Française 17, Paris.

Hanut, Frédéric \& Henrotay, Denis (éd.), 2014, Du bûcher à la tombe. Les nécropoles gallo-romaines à incinération en Wallonie, Catalogue d'exposition du musée archéologique d'Arlon, Namur.

HASSELIN-Rous, Isabelle, 2013, « La dînette de la petite fille d'Érétrie : un jouet fonctionnel ? », Archéothéma 31, p. 21-22. JehASSE, Laurence, 1980, « Les objets d'os d'Aléria (Corse) » dans Danielle Stordeur (éd.), Objets en os, historiques et actuels. Première réunion du groupe de travail $n^{\circ} 6$ sur l'industrie de l'os, GIS, Lyon, mars 1979, Lyon, p. 41-48.

Jehasse, Jean \& JehASSE, Laurence, 1973, La nécropole d'Aléria (1960-1968), Gallia supplément 25, Paris.

Jehasse, Jean \& Jehasse, Laurence, 2001, Aléria. Nouvelles données de la nécropole. Maison de l'Orient et de la Méditerranée Jean Pouilloux, Lyon (Travaux de la Maison de I'Orient méditerranéen 34).

Lнôte, Jean-Marie, 1999, « Jeux et démocratie», dans Daniel Tarschys (éd.), Art et conflit : le processus artistique entre rêve et état de veille, colloque international, Paris, 5-7 mai 1997, Strasbourg, p. 87-108.

LUCE, Jean-Marc, 2011, « From Miniature Objects to Giant Ones: The Process of Defunctionalisation in Sanctuaries and Graves in Iron Age Greece », Pallas 86, p. 53-73.

Manniez, Yves, 1984, Les objets en os d'époque gallo-romaine en Languedoc oriental (du Lez au Rhône), Mémoire de maîtrise inédit d'histoire de l'art et d'archéologie, Université Montpellier III.

MannIeZ, Yves, 1999, Les pratiques funéraires en Narbonnaise méditerranéenne (partie occidentale) du III ${ }^{e}$ au VIII ${ }^{e}$ s., Thèse de doctorat inédite sous la direction de M. Jean Guyon, Université Aix-Marseille I - Université de Provence.

Manniez, Yves, 2010, «Contribution à l'étude des dés en os d'époque romaine de la cité de Nîmes (F) 》, Instrumentum 32, p. 18-22.

MANnIEZ, Yves, 2012, «Le petit mobilier de la tombe SP1001 », dans Marie Rochette et al., « Découverte de deux nouvelles tombes du Haut-Empire dans le quartier Hoche-Sernam à Nîmes (Gard) », Revue Archéologique de Narbonnaise 45, p. 221-246.

Manniez, Yves, 2016, « Mobilier des tombes à amulettes », dans Valérie Bel et al., « Deux ensembles funéraires d'époque romaine, avenue Jean-Jaurès à Nîmes (Gard) », Revue Archéologique de Narbonnaise, Supplément 46, p. 158-166.

MefrRe, Joël-Claude, 1985, « Sépultures à incinération du $1^{\text {er }} \mathrm{s}$. découvertes à Séguret (Vaucluse) 》, Bulletin archéologique de Provence 15, p. 15-27.

NikUlina, Elena \& Schmölcke, Ulrich, 2008, « Les osselets, ancêtres du jeu de dés », Pour la Science 365, p. 40-43. PhILPOT, Robert, 1991, Burial Practices in Roman Britain. A Survey of Grave Treatment and Furnishing A.D. 43-410, Oxford (British Archaeological Reports, British Series 219).

Plumier, Jean, 1986, Tumuli belgo-romains de la Hesbaye occidentale : Séron, Hanret, Bois de Buis, Penteville, Musée Archéologique de Namur, Namur.

Poplin, François, 1991, « Réflexions sur l'astragale d'or de Varna, les pieds fourchus et la métallisation de l'animal », dans Jean-Pierre Mohen (éd.), Découverte du métal, Paris, p. 31-42.

Poplin, François, 1992, «Les jeux d'osselets antiques », Les Dossiers de l'Archéologie 168, p. 46-47.

Provost, Michel (éd.), 1999, Le Gard, Carte Archéologique de la Gaule, 30/3, (Pré-inventaire archéologique publié sous la responsabilité de Michel Provost), Paris.

PY, Michel, 1990, Culture, économie et société protohistoriques dans la région nimoise, Rome - Paris (Collection de l'École Française de Rome 131).

SCHÄDLER, Ulrich, 1996, « Spielen mit Astragalen », Archäologischer Anzeiger 1, p. 61-73.

Schädler, Ulrich, 2007, « The Doctor's Game - New Light on the History of Ancient Board Games », dans Philip Crummy et al., Stanway: An Elite Burial Site at Camulodunum, London (Britannia Monograph Series 24), p. 359-375.

Schwaller, Martine et al., à paraître. La nécropole du deuxième âge du Fer d'Ensérune (Hérault).

SuDRES, Georges, 1981, La nécropole gallo-romaine de Courac ([Tresques], Gard), Sites 11, 17-24.

WhItTLE, Alasdair W.R., 1996, Europe in the Neolithic: The Creation of New Worlds, Cambridge. 